\title{
Characterisation of Natural Oils as Carrier Fluids for Magnetorheological Fluids
}

\author{
Ram Rohit Vannarth, Raj Dhake, S Vishal Kanna and Safal Sharad Saraf
}

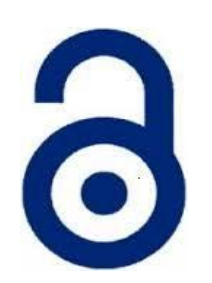

\author{
Received: 16 September 2019 \\ Accepted: 14 November 2019 \\ Published: 15 December 2019 \\ Publisher: Deer Hill Publications \\ (c) 2019 The Author(s) \\ Creative Commons: CC BY 4.0
}

\begin{abstract}
The field of application of Magnetorheological fluids (MRF) is widening. The carrier fluids being used now are synthetic, expensive and non-biodegradable. Hence, there is a need for looking for better and inexpensive alternatives. This study was intended to uncloak alternatives to the synthetic carrier fluids by taking four natural oils and conducting various tests. The four natural oils, viz, Simarouba Oil, Mahua Oil, Groundnut oil, Flaxseed oil and synthetic Silicone oil were taken and tests concerning Magnetorheological fluids like density, kinematic viscosity, flash and fire point, pour point, etc., were conducted according to standards in a licensed laboratory. Based on the various tests conducted, the four natural oils have shown remarkable potential compared with commonly used silicone oil to be used as carrier fluids.
\end{abstract}

Keywords: Magnetorheological fluids, Carrier fluids, Carrier fluid properties, Inexpensive alternatives, Natural oils

\section{INTRODUCTION}

Magneto-rheology is a genre of rheology which addresses the research of flow behaviour and deformation of materials subjected to magnetic field. In 1949, Jacob Rabinow found Magnetorheological (MR) liquids which are suspensions of non-colloidal $(0.05-10 \mu \mathrm{m})$, multi-domain, magnetically soft particles in organic or water based liquids known as carrier fluids [1]. They comprise of magnetisable particles, non-magnetisable suspending fluids and additives [2]. The most common MR substances exist in the liquid state [3]. MR fluids conduct similarly, to Newtonian fluids in the void of subjected magnetic field; under the influence of the external magnetic field, the behaviour of MR fluids can be outlined by the Bingham plastic model [4]. The properties of these fluids (such as viscosity, yield stress, etc.) alter according to the exerted magnetic field. Hence, they can be considered as smart materials [5]. The particles of MRFs are magnetically multi-domain, which induces a magnetic dipole in each particle, leading to strong forces being developed between the particles. Hence, a network of particles is developed and the MRF changes to semi-solid state or viscoelastic solid from liquid state, temporarily. Rheological attributes of magnetorheological fluids, for example, yield stress and apparent viscosity can be promptly monitored by applying a magnetic field [6]. Hence, these fluids behaves like non-Newtonian fluids under an external magnetic field [7].

For various applications of magnetorheological fluids (such as MR brakes, dampers, etc.), the response time of MRFs is quite significant. This response time has a range of 10-20 milliseconds, which depends on the design of the magnetic circuit. So, MRFs, for mechanical applications can illustrate dynamic yield stress up to $100 \mathrm{kPa}$, according to its flux density, amplitude and composition [5]. Magneto-rheological fluid technology is now impressively applied in various low and high-volume applications, which have turned out to be advantageous commercially. Conventional MRFs uses carrier liquids which has certain limitations such as high cost, non- biodegradable and ease of availability has inspired us to look for alternative natural carrier fluid which is eco-friendly, available in plenty in India and are less expensive. In this paper, the properties of four natural fluids- Simarouba Oil, Mahua Oil, groundnut oil, and flaxseed oil as a potential carrier fluid is compared with silicone oil which is a standard carrier fluid. Various tests have been conducted as per standards on these oils to compare the desirable properties such as fire point, flash point, etc. The influencing factors for considering natural carrier fluid of MR Fluids were systematically discussed and analysed.

Ram Rohit Vannarth $\bowtie$, Raj Dhake, S Vishal Kanna, Safal Sharad Saraf

Department of Mechanical Engineering

BMS College of Engineering, Bangalore, India

E-mail: ramrohit.mech@bmsce.ac.in

Reference: Vannarth, R. R., Dhake, R., Kanna, V. and Saraf, S. S. (2019). Characterisation of Natural Oils as Carrier Fluids for Magnetorheological Fluids. International Journal of Engineering Materials and Manufacture, 4(4), 164-169. 


\section{MATERIALS AND PREPARATION \\ 2.1 Simarouba Oil}

The seeds from the Simarouba glauca tree hold around60 -75\% of oil. The main uses of the oil is for the production of biodiesel, being edible it is widely used in preparation of bakery products, vegetable oil vanaspati and/or margarine. Upon extraction of the oil, the seeds can be used as a binding agent for waste water treatment processes. For this study, Simarouba seeds were collected from different part of Karnataka, India from which the oil was extracted by cold-pressing the dried kernel of Simarouba.

\subsection{Mahua Oil}

The oil extracted from the seeds of the Mahua tree (Madhuca Indica) is called Mahua oil. The seeds are produced after a 10-11 year growth period of the Mahua tree. The derivation of the oil from the sun-dried seeds was done by means of an expeller and the average yield is around $21-31 \%$ per kernel. Natural Mahua oil were yellow in appearance since they are properly stored without any harmful preservatives whereas the commercial Mahua oil was also yellow in colour but has a unbearable odour and taste because of the presence of excess fatty acids.

\subsection{Silicone Oil}

Any liquid polymerized siloxane with organic side chains can be acknowledged as silicone oil. The crucial member of the silicone oil structure is polydimethylsiloxane. The most efficient method of producing in which cross linked silicone particles are evenly scattered in amino-modified silicone oil was by the extraction of water from the liquid after mixing an aqueous suspension of cross-linked silicone particulates of mean diameters 0.1 to $500 \mu \mathrm{m}$ to an aqueous mixture of amino based silicone oil having an mixture particle diameter lying in the range 0.05 to $100 \mu \mathrm{m}$ [8].

\subsection{Flaxseed Oil}

Flaxseed oil, also familiar as Linseed oil or flax oil, is derived from the parched, matured seeds of the flax plant (Linumusitatissimum) $[9,10]$. Most of the commercially grown flaxseed contains 20-25\% protein per weight and $40-45 \%$ of oil. The flaxseed oil for comparison had been extracted from the cold pressing industry. Flax for commercial use is squeezed and then boiled which is then exposed to a high temperature to commence oxidation and polymerization [11]. The flax obtained is crushed and pressed using a modern steel press to get the oil out.

\subsection{Groundnut Oil}

Groundnut oil, also known as Arachis oil, is a bland taste vegetable oil derived from peanuts. The oil possesses an intense peanut flavour and odour [12]. The raw material required for the preparation of groundnut oil is groundnut seed. Firstly, groundnut seeds are cleaned so that the oil was not contaminated. Removal of the outer episperm was critical because it doesn't contain oil. For grinding processes seeds are not usually pressed whole since oil removal is more effective if the seed is in smaller proportions. Heating was the concluding step for preparing the base substance for the extraction of oil.

\section{EXPERIMENTAL METHOD}

\subsection{Density Test}

Density is mass of the liquid per unit volume or it is also the compactness of the molecules of liquid measured at $15^{\circ} \mathrm{C}$. A Specific gravity bottle was used to measure density [13]. It was washed thoroughly by distilled water and acetone and then dried in the furnace for about $5-10$ minutes. The weight of empty specific gravity bottle was taken as $W_{1}$. The cylinder containing the sample in the vertical position was placed in a location free from air and weight of specific gravity bottle with the sample was taken as $W_{3}$. Finally, the weight of an empty specific gravity bottle containing distilled water was taken as $W_{2}$ [14]. The experimental setup used for this test is as shown in the Figure 1. Density was measured as per IS:1448 (Part 16) [15]. Density is then calculated by:

$$
D=\frac{(W 3-W 1) * 1000}{(W 2-W 1)}
$$

Where, $D=$ Density $\left(\mathrm{Kg} / \mathrm{m}^{3}\right), W_{1}=$ weight of empty specific gravity bottle $(\mathrm{Kg}), W_{2}=$ the weight of an empty specific gravity bottle containing distilled water $(\mathrm{Kg}), W_{3}=$ weight of specific gravity bottle with the sample $(\mathrm{Kg})$.

\subsection{Flash Point and Fire Point}

The minimal temperature at which the test flame triggers the vapour above the sample to give a momentary distinct flash is called Flash Point and the temperature at which the oil ignites and continues to combust for no less than 5 seconds is called as Fire Point. The oil sample was placed in the cup of the Pensky Martens apparatus, as shown in Figure 2, which was used to estimate the flash and fire point of the sample and then heated at a specific rate [16]. In this process, a limited test flame was directed on the cup periodically to ignite the oil sample. Initially, the cup and the accessories are cleaned thoroughly for accurate values. Thermometer and test fires are placed on the cup and usually, a high range of thermometer was used if the flashpoint of oil will be above $105^{\circ} \mathrm{C}$. The temperature was increased gradually and the surface of the oil was checked for the phenomenon of flash and fire point. Flash and Fire point are measured as per IS:1448 (Part 66) [17]. 


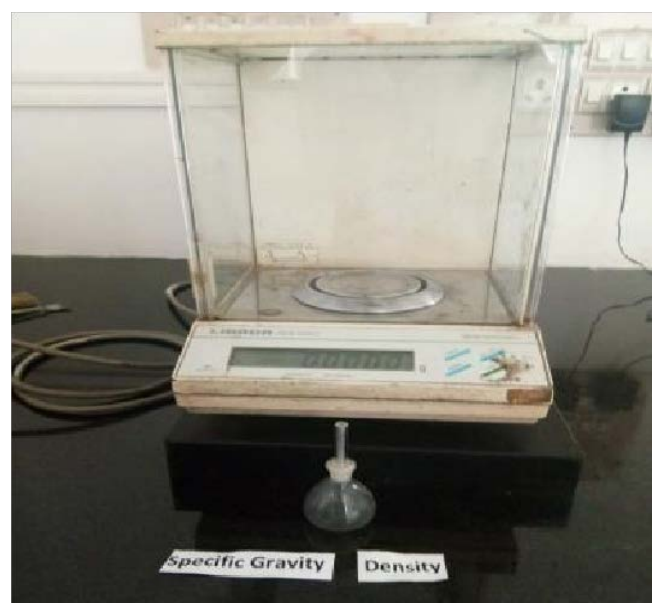

Figure 1: Experimental setup for density test as per IS:1448 (Part 16) standards.

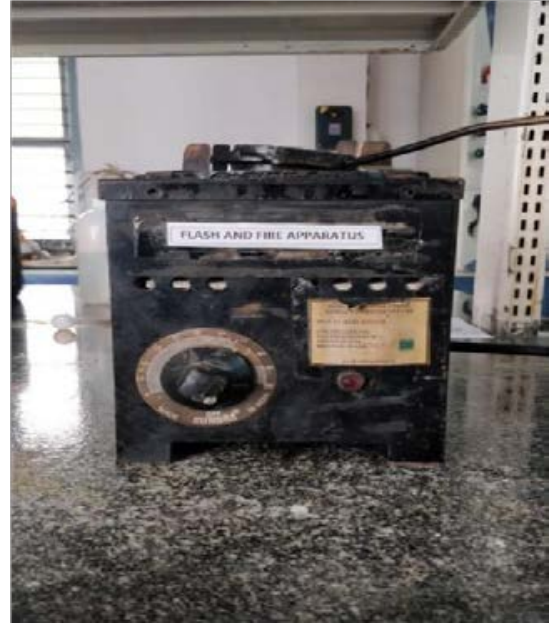

Figure 2: Experimental setup for Flash and Fire Point test as per IS:1448 (Part 66) standards.

\subsection{Kinematic Viscosity}

A device called as a viscometer is used to determine the kinematic viscosity and the principle on which it works is based on the fact that time of flow of a fluid of fixed volume is proportional to its kinematic viscosity at $40^{\circ} \mathrm{C}$ and $100^{\circ} \mathrm{C}$. The viscosity was recorded through viscometer to which paraffin liquid was added to keep a check on the temperature and to evenly circulate the heat. The reading was taken once the particular temperature was reached and the time was taken until it reaches that level was measured using a stop clock in terms of seconds and it is called flow time which is denoted as " $\mathrm{t}$ ". The product of flow time and calibration constant (or viscometer constant which has a value of 0.0640 ) of the viscometer gives the kinematic viscosity [18]. The experimental setup used for this test is as shown in Figure 3. Kinematic viscosity was calculated as per IS:1448 (Part-25).

Where, $t=$ flow time

$$
\text { Kinematic Viscosity }=0.0640 * \mathrm{t}
$$

\subsection{Viscosity Index}

Viscosity index gives how the oil will act at a particular temperature. Higher Viscosity Index indicates a relatively minor change of viscosity with temperature [19]. Viscosity index is a broadly employed and recognised criterion of the variability in kinematic viscosity due to changes in the temperature of the oil being used as a carrier fluid between $40^{\circ} \mathrm{C}$ and $100^{\circ} \mathrm{C}$. It was calculated by taking the oils kinematic viscosity at $40^{\circ} \mathrm{C}$ as $\mathrm{U}$ and the oils viscosity at $100^{\circ} \mathrm{C}$ as $L$ and $H$ [20], the values of which can be obtained from the ASTM D2270 [21].

$$
V I=\frac{100(L-U)}{(l-H)}
$$

Where, V.I. = Viscosity Index, $\mathrm{L}=$ kinematic viscosity at $40^{\circ} \mathrm{C}$ of an oil of $\mathrm{O}$ (zero) viscosity index possessing the same kinematic viscosity at $100^{\circ} \mathrm{C}$ as the oil whose viscosity index is to be calculated (cSt), $\mathrm{H}=$ kinematic viscosity at $40^{\circ} \mathrm{C}$ of an oil of 100 viscosity index possessing the similar kinematic viscosity at $100^{\circ} \mathrm{C}$ as the oil whose viscosity index is to be computed (cSt), $\mathrm{U}=$ kinematic viscosity at $40^{\circ} \mathrm{C}$ of the oil whose viscosity index is to be computed (cSt).

\subsection{Pour Point}

It is the temperature below which the flow characteristics of the liquid are lost. High Pour Point is usually associated with a high content of paraffin. Warm oil sample $(50 \mathrm{ml})$ was taken in a $100 \mathrm{ml}$ beaker and placed in the refrigerator. In every 5 minutes interval, the beaker is inspected by holding it in a horizontal position for a couple of seconds before cooling back. The Pour Point was reached when the oil surface stays in a vertical position and when tilted for 5 seconds, does not sag. The thermometer was inserted at this point and the Pour Point is 3 degree Celsius higher than the temperature reading on the thermometer. The experimental used for this test is as shown in Figure 4. Pour Point was measured as per IS:1448 (Part10) [22].

$$
\text { Pour point }=\mathrm{X}^{\circ} \mathrm{C}+3^{\circ} \mathrm{C}
$$

Where, $\mathrm{X}^{\circ} \mathrm{C}=$ thermometer reading 


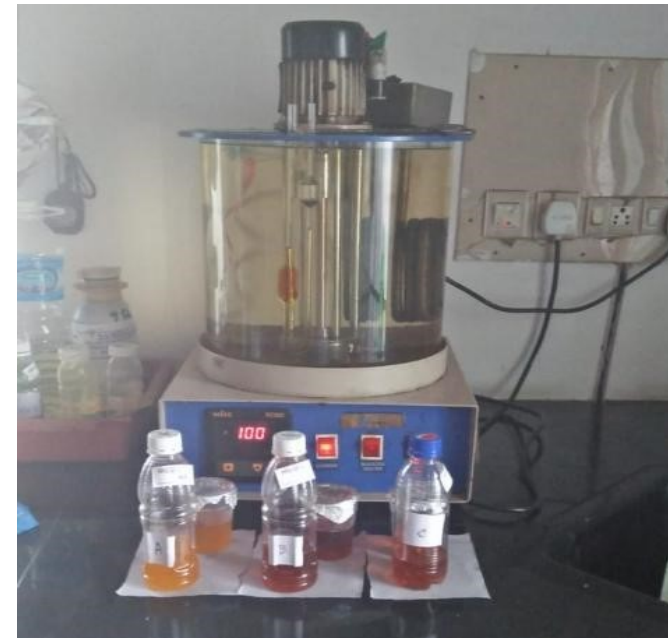

Figure 3: Experimental setup for Kinematic Viscosity test as per IS:1448 (Part-25) standards.

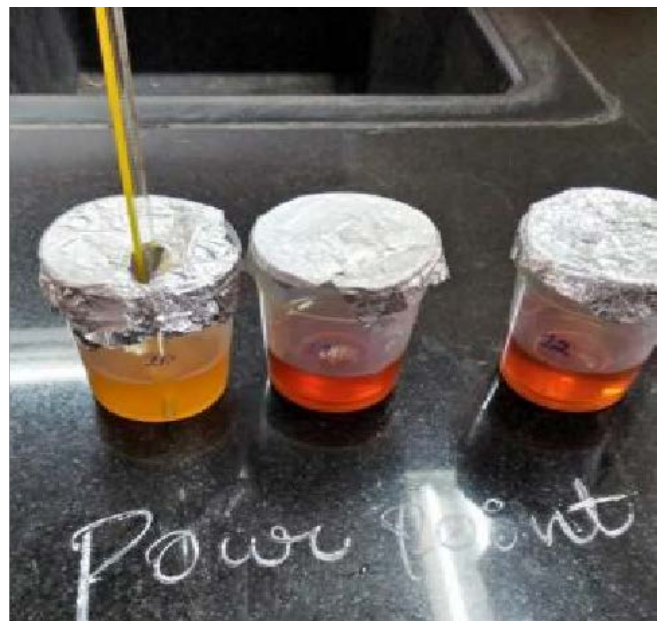

Figure 4: Experimental setup for Pour Point test as per IS: 1448 (Part-10) standards.

\subsection{Water Content [Karl Fischer Method]}

This test was employed to measure the water content in the oil by employing the chemical reaction between water with iodine and sulphur dioxide with methanol and an organic base such as pyridine. Volumetric titration was employed for the determination of water content. A Karl Fischer reagent and methanol are used in the titration; 50 $\mathrm{ml}$ of ethanol was added in the titration vessel. The oil to be tested was taken in a syringe. An electromagnetic stirrer was used for thorough mixing and the Karl Fischer reagent was added till there was sudden and constant deflection for about 30 seconds. The oil in the syringe was introduced into the titration instrument and was titrated versus the Karl Fischer reagent to find the endpoint of the reaction. The readings noted give the water content. The experimental setup used for this test is as shown in Figure 5. Water content was measured as per ASTM D6 304 [23]. Karl Fischer reaction mechanism:

$$
\text { Where, RN = base } \begin{gathered}
\mathrm{CH}_{3} \mathrm{OH}+\mathrm{SO}_{2}+(\mathrm{RN})<=>[\mathrm{RN} \mathrm{H}] \mathrm{SO}_{3} \mathrm{CH}_{3} \\
\mathrm{H}_{2} \mathrm{O}+\mathrm{I}_{2}+[\mathrm{RN} \mathrm{H}] \mathrm{SO}_{3} \mathrm{CH}_{3}+2 \mathrm{R} \mathrm{N}<=>[\mathrm{RN} \mathrm{H}] \mathrm{SO}_{4} \mathrm{CH}_{3}+2[\mathrm{RN} \mathrm{H}] \mathrm{I}
\end{gathered}
$$

\subsection{Sulphur Content [Advanced Bomb Calorimeter]}

This test was used to measure the sulphur content in the oil. The instrument used (bomb instrument) was prepared by cutting an ignition wire of $100 \mathrm{~mm}$ length and is coiled in the middle. About $5 \mathrm{ml}$ of $\mathrm{Na}_{2} \mathrm{CO}_{3}$ solution was added and it was rotated such that the interior surface of the bomb was moistened by the solution. The required quantity of sample and white oil (liquid paraffin) is introduced. It was arranged in such a way that the sample was placed below the bomb. Oxygen was then passed into the bomb instrument at the desired pressure. The bomb was submerged in a cold distilled water bath for ignition and the ends are connected to an open electrical circuit. The ignition was carried out by closing the circuit. The interior of the bomb instrument was rinsed thoroughly by a jet of water and the washing obtained is collected in a beaker. The beaker was heated just below the boiling point of the liquid present and to which conc. $\mathrm{HCl}$ and $\mathrm{BaCl}_{2}$ drops are added and stirred well. The experimental setup used for this test is as shown in Figure 6. Sulphur content was measured as perls:1448 (Part-33) [24].

$$
\text { Sulphur weight }=\frac{(A-B) * 13.69}{w}
$$

Where, $A=$ mass of barium sulphate from sample $(g), B=$ mass of barium sulphate from blank $(g), W=$ weight of the sample. 


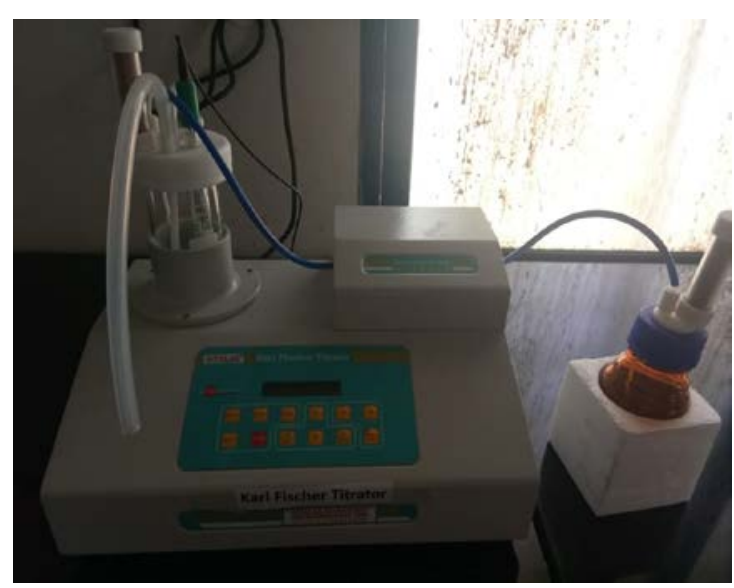

Figure 5: Experimental setup for Water Content test as per ASTM D6 304 standards

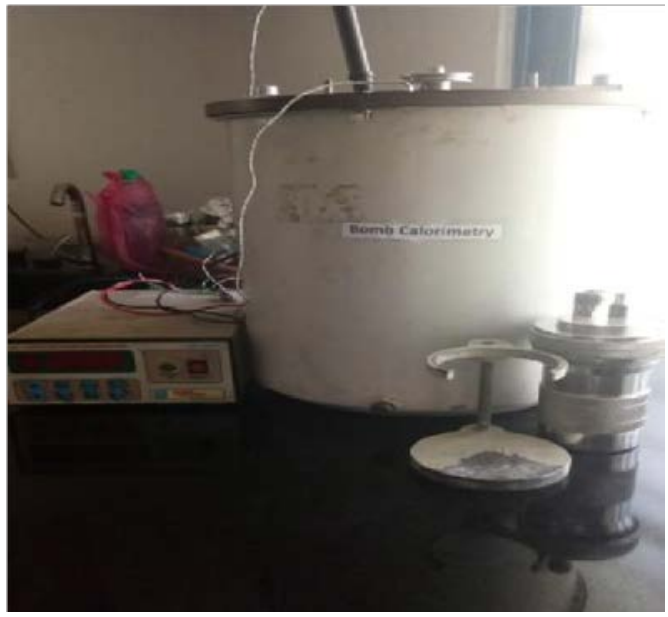

Figure 6: Experimental setup for sulphur content test as per IS:1448 (Part-33) standards.

Table 1: Properties of oils

\begin{tabular}{|c|c|c|c|c|c|c|}
\hline & Simarouba oil & Mahua oil & Silicone oil & Flaxseed oil & Groundnut oil & Test method \\
\hline $\begin{array}{l}\text { Kinematic Viscosity } \\
@ 40^{\circ} \mathrm{C}(\mathrm{cSt})\end{array}$ & 56.2 & 51.97 & 54.1 & 29.59 & 35.79 & IS:1448 (Part25) \\
\hline $\begin{array}{l}\text { Kinematic Viscosity } \\
@ 100^{\circ} \mathrm{C} \text { (cSt) }\end{array}$ & 33.2 & 30.68 & 33.8 & 8.38 & 8.79 & IS:1 448 (Part25) \\
\hline $\begin{array}{l}\text { Density@15 } 15^{\circ} \mathrm{C} \\
\left(\mathrm{kg} / \mathrm{m}^{3}\right)\end{array}$ & 968.14 & 958.85 & 961.79 & 924.89 & 916.92 & IS:1448 (Part16) \\
\hline Viscosity Index & 543.12 & 546.69 & 564.64 & 282.42 & 196.78 & ASTM D2270 \\
\hline Flash Point $\left({ }^{\circ} \mathrm{C}\right)$ & 144 & 142 & 110 & 124 & 130 & IS:1448 (Part66) \\
\hline Fire Point $\left({ }^{\circ} \mathrm{C}\right)$ & 150 & 144 & 114 & 126 & 132 & -- \\
\hline Water Content (\%) & 0.36 & 0.23 & 0.67 & 0.61 & 0.55 & ASTM D6 304 \\
\hline Sulphur Content (\%) & 0.05 & 0.22 & 0.53 & 0.5 & 0.61 & IS :1448 (Part33) \\
\hline Pour Point $\left({ }^{\circ} \mathrm{C}\right)$ & -15 & -18 & -12 & -14 & -10 & IS:1448 (Part10) \\
\hline
\end{tabular}

\section{RESULTS AND DISCUSSIONS}

Referring to Table 1, we can say that the of the four natural carrier oils, Mahua Oil $=958.85 \mathrm{~kg} / \mathrm{m}^{3}$, Groundnut $=916.92 \mathrm{~kg} / \mathrm{m}^{3}$, Flaxseed oil $=924.89 \mathrm{~kg} / \mathrm{m}^{3}$ have lower density compared with traditionally used silicone oil which has a slightly higher density, silicone oil $=961.79 \mathrm{~kg} / \mathrm{m}^{3}$; exception being Simarouba oil which has a higher density than silicone oil. The viscosity of oil is important for its cooling and lubricant properties. The four natural carrier oils have comparatively lower viscosity (at $40^{\circ} \mathrm{C}$ and $100^{\circ} \mathrm{C}$ ) than silicone oil which results in faster cooling and better lubrication in MR fluids applications.

Natural oils have a lower viscosity index which indicates they require a lower temperature to reduce viscosity compared to silicone oil. Flashpoint and Fire point of oils demonstrates the likely presence of flammable materials in relatively non-flammable materials or non-volatile. The natural oils have a higher Flash and Fire point which prevents them from undergoing combustion at a lower temperature, which in turn makes them quite safer than silicone oil. Water content is the amount of water present in the fluid in terms of the percentage of the composition. The more the water content in the base fluid, the more is the magnetorheological fluid stability but at price of being more corrosive. The natural oils have slightly less water content as compared to the silicone oil. Hence, the magnetorheological stability would be slightly more in the case of silicone oil $(0.67 \%)$. When considering the sulphur content there Silicone and Groundnut oils have higher values compared with the other oils, hence, the corrosion resistance decreases. Pour point of Simarouba $\left(15^{\circ} \mathrm{C}\right)$ and Mahua oils $\left(-18^{\circ} \mathrm{C}\right)$ points out the oil's ability to flow in cold conditions.

\section{CONCLUSIONS}

The characteristics of the natural oils relevant to be used as carrier fluids for MR fluids have been studied in this research. Among the four natural oils Flaxseed, Groundnut, Mahua oil have significantly lower viscosity at both $40^{\circ} \mathrm{C}$ and $100^{\circ} \mathrm{C}$. Since the viscosity of Flaxseed oil is least $\left(29.59 \mathrm{cSt} @ 40^{\circ} \mathrm{C}\right.$ and $\left.8.38 \mathrm{cSt} @ 100^{\circ} \mathrm{C}\right)$ it has the best MR 
response among the five oils tested. The density of Simarouba Oil is $968.14 \mathrm{~kg} / \mathrm{m}^{3}$ is greater compared to the traditionally used Silicone oil which has density of $961.71 \mathrm{~kg} / \mathrm{m}^{3}$. hence the sedimentation stability and yield of Simarouba oil is more. Both Simarouba and Mahua oils have low percentage of sulphur and water content, indicating they are less corrosive in nature. Pour Point temperature of Simarouba $\left(-15^{\circ} \mathrm{C}\right)$ and Mahua oils $\left(-18^{\circ} \mathrm{C}\right)$ are relatively low, hence they can be stored at such low temperature without them losing their flow ability. The Flash and Fire point of Simarouba and Mahua oil is high preventing them from undergoing combustion at a lower temperature, which in turn makes them quite safer than silicone oil. Silicone oil is expensive and artificially synthesized oil whereas Simarouba Oil, Mahua Oil, Groundnut oil and Flax Seed oil are comparatively inexpensive, easily available and biodegradable. Thus, we can say that Simarouba Oil has the most desirable MR carrier fluid properties among Mahua Oil, Flax Seed oil and Groundnut Oil. Hence Simarouba Oil show good potential as a base oil for MR fluids applications.

\section{REFERENCES}

[1] A. Muhammad, X. Yao, and Z. Deng, "Review of magnetorheological (MR) fluids and its applications in vibration control,” J. Mar. Sci. Appl., 5 (3), 17-29, Sep. 2006.

[2] Fernando D G and Carlson J D in 10th Int. Conf. on ER Fluids, MR Suspensions, 2006, 165.

[3] M. R. Jolly, "Properties and Applications of Magnetorheological Fluids," MRS Proc., 604, 167, Feb. 1999.

[4] J. Q. Zhang, J. Zhang, and Q. Jing, "Effect of seven different additives on the properties of MR fluids," J. Phys. Conf. Ser., 149, 012086, Feb. 2009.

[5] B. K. Kumbhar, S. R. Patil, and S. M. Sawant, "Synthesis and characterization of magneto-rheological (MR) fluids for MR brake application,” Eng. Sci. Technol. an Int. J., 18 (3), 432-438, Sep. 2015.

[6] M. Ashtiani, S. H. Hashemabadi, and A. Ghaffari, "A review on the magnetorheological fluid preparation and stabilization,” J. Magn. Magn. Mater., 374, 716-730, Jan. 2015.

[7] R. Kciuk, Monika and Turczyn, "Properties and application of magnetorheological fluids," J. Achiev. Mater. Manuf. Eng., 18 (1-2), 2006.

[8] A. Phuly, “( 12 ) Patent Application Publication ( 10 ) Pub . No .: US 2012 / 0047830 A1,” 1, (19), 2012.

[9] F. N. Jones, "Alkyd Resins," in Ullmann's Encyclopedia of Industrial Chemistry, Weinheim, Germany: WileyVCH Verlag GmbH and Co. KGaA, 2003.

[10] S. Rwahwire, B. Tomkova, A. P. Periyasamy, and B. M. Kale, "Green thermoset reinforced biocomposites," in Green Composites for Automotive Applications, Elsevier, 2019, 61-80.

[11] P. Kolodziejczyk, L. Ozimek, and J. Kozłowska, "The application of flax and hemp seeds in food, animal feed and cosmetics production," in Handbook of Natural Fibres, Elsevier, 2012, 329-366.

[12] X. Liu et al., "Changes in Volatile Compounds of Peanut Oil during the Roasting Process for Production of Aromatic Roasted Peanut Oil,” J. Food Sci., vol. 76, no. 3, pp. C404-C412, Apr. 2011.

[13] R. Ramachandran, S. Balasubramanian, G. Aridoss, P. Parthiban, G. Yamuna, and S. Kabilan, "Synthesis and studies of semiconducting piperazine-aniline copolymer," Eur. Polym. J., 42 (8), 1885- 1892, Aug. 2006.

[14] N. J. John, P. Selvarajan, S. B. J. Silviya, and C. K. Mahadevan, "Growth and Characterization of Disodium Hydrogen Orthophosphate (DSHP) Single Crystals," Mater. Manuf. Process., 22 (3), 379-383, Mar. 2007.

[15] Bureau of Indian Standards, Methods of test for petroleum and its products, Part 16. 1990.

[16] D. Ravichandra, R. K. Puli, and V. P. Chandramohan, "Production and Comparison of Fuel Properties for Various Biodiesels," 2019, 267-276.

[17] Bureau of Indian Standards, Methods of test for petroleum and its products, Part 66. 1969.

[18] Bureau of Indian Standards, Methods of Test for Petroleum and its Products, Part 25. 1976.

[19] J. Speight and D. I. Exall, Refining Used Lubricating Oils. CRC Press, 2014.

[20] D. Derawi et al., "Palm Olein as Renewable Raw Materials for Industrial and Pharmaceutical Products Applications: Chemical Characterization and Physicochemical Properties Studies," Adv. Mater. Sci. Eng., 2014, $1-5,2014$.

[21] ASTM, Standard Practice for Calculating Viscosity Index from Kinematic Viscosity at $40{ }^{\circ} \mathrm{C}$ and $100{ }^{\circ} \mathrm{C} .2016$.

[22] Bureau of Indian Standards, Methods of test for petroleum and its products, Part 10. 2012.

[23] ASTM, Standard Test Method for Determination of Water in Petroleum Products, Lubricating Oils, and Additives by Coulometric Karl Fischer Titration. 2016.

[24] Bureau of Indian Standards, Methods of test for petroleum and its products, Part 33. 1991. 